\title{
Association between Body Mass Index and depression: the "fat and jolly" hypothesis for adolescents girls
}

Anne Revah-Levy ${ }^{1,2,3^{*}+}$, Mario Speranza ${ }^{1,2,4+}$, Caroline Barry ${ }^{1,2}$, Christine Hassler ${ }^{1,2}$, Isabelle Gasquet ${ }^{1,2,5}$, Marie-Rose Moro ${ }^{1,2,6}$ and Bruno Falissard ${ }^{1,2,7}$

\begin{abstract}
Background: Results concerning the association between Body Mass Index (BMI) and depression in adolescence are conflicting, some describing a linear association (increase in BMI with level of depression), some a U-shaped association (both underweight and obesity are associated with high levels of depression), and they mostly concern small samples. The purpose of this study was to describe the association between BMI and depression in a large representative sample of French adolescents.

Methods: The association between BMI and depression, measured on the Adolescent Depression Rating Scale (ADRS), was tested in a French national representative sample of 39542 adolescents aged 17. Self-report data is derived from the 2008 ESCAPAD study, an epidemiological study based on a questionnaire focused on health and drug consumption. We used spline function analysis to describe the association between BMI and depression.

Results: The association between BMI and depression is significant $(p<0.001)$ and non-linear for both genders, with no effect of parental working and marital status. For boys, there is U-shaped association. For girls the shape of the association is complex and shows inverted convexity for high levels of BMI. The spline shows higher scores for depression among overweight girls than among obese girls.

Conclusion: There is evidence for a gender difference in the association between BMI and depression in adolescents, supporting the need to study boys and girls separately. Overweight adolescent girls are more likely to be depressed than obese adolescent girls, giving support for "fat and jolly" hypothesis not only among older women but also among adolescent girls.
\end{abstract}

\section{Background}

Adolescence is a critical period, whether for weight problems or for depression. Obesity and depressive disorders in adolescence in particular are risk factors for chronic pathologies in adulthood, the medical and economic consequences of which are central public health issues [1-4]. Numerous covariates of the association between variation of weight and depression have been described, especially in adolescence, such as age, gender, socioeconomic status of the parents, family structure, level of education, race/ethnicity, body image, [5-9]. A

\footnotetext{
* Correspondence: anne.revah-levy@ch-argenteuil.fr

+ Contributed equally

'INSERM, U-669 PSIGIAM, Paris, F-75679, France

Full list of author information is available at the end of the article
}

multifaceted approach to explaining child and adolescent variations in weight has suggested that the home environment and socioeconomic status are important considerations $[10,6]$.

While only longitudinal studies are likely to demonstrate the complex underlying mechanisms linking variation in weight and depression, such as a bidirectional association, with potential moderators such as physical activity, eating patterns, or depression severity [11-13], cross-sectional studies in a large-scale community sample do contribute to describing the characteristics of the association between weight and depression [14]. To date, all kinds of associations have been described at different ages: a positive association between depression and obesity (more severe depression is associated with

\section{() Biomed Central}


greater obesity) [15-18], a negative association (more severe depression is associated with a lesser degree of obesity)[19], no association [20,21]. We found few studies in which the existence of a U-curve was tested [22-24]. According to Wardle, the case for a relationship between adolescent obesity and depression is not yet proven. The heterogeneity of results in this area could be related to different factors. Firstly adolescence is a period of bodily change, with a particular impact of weight change, probably more complex than in adults. Secondly, covariables envisaged differ from one study to another. And finally heterogeneity in results may also arise from the different methods used to measure depression $[4,19]$.

Indeed, the variability of criteria to define categories of weight and depression from one study to another render interpretation of results rather difficult. There is also a problem with the use of depression measures that contain an item or items concerning appetite or weight, which could bias results.

To date, there has been no study on this question in any European country on a large sample of adolescents aged 17 and representative of that population. The aim of the present study, in the largest-ever representative sample of French adolescents aged 17 years-old, was i) to determine the prevalence of overweight and obesity, ii) to determine the prevalence of depression, using a validated tool, the Adolescent Depression Rating Scale (ADRS) [25], which contains no item on weight, appetite, or body image, and iii) to investigate the association between BMI and depression controlling for working and marital status of the parents.

\section{Method}

\section{Participant selection}

Participants were recruited in metropolitan France (i.e. excluding overseas territories) between March $15^{\text {th }}$ and March $31^{\text {st }} 2008$ during the National Defense Preparation Day (Journée d'Appel de Préparation à la Défense JAPD). The JAPD is a civic and military information session that is required of all adolescents aged 17, and mandatory to sit public examinations (e.g., driving license, university exams). All French adolescents aged 17 years are called to participate in these national days in one of the 250 centers in France. In all, 764000 adolescents aged 17 were living in metropolitan France in 2008. Among these, 44733 (5.9\%) subjects aged 17 years were invited to participate in the Survey on Health and Behavior, called ESCAPAD [26], a cross-sectional survey conducted by the French Monitoring Center for Drugs and Drug Addiction (Observatoire Français des Drogues et des Toxicomanies- OFDT), and administered during JAPD days in collaboration with the National Service Bureau of the Army. The sample finally included in this study comprised 39542 French subjects living in metropolitan France ( $\mathrm{N}=19,658$ girls and 19,884 boys). This represents $5.2 \%$ of adolescents aged 17 years living in metropolitan France (5.3\% for girls and 5.1\% for boys). The survey obtained the public statistics general interest seal from the Comité National de l'Information Statistique - CNIS, as well as the approval of ethics committee (Commission Nationale d'Information et Liberté).

\section{Measures of BMI and depression}

From the ESCAPAD questionnaire, we used the data available about weight, height, and ADRS scores.

BMI was calculated as weight in kilograms divided by height in meters squared, based on self-reported heights and weights. According to WHO guidelines [27], adolescents were classified as underweight $(\mathrm{BMI}<=17.0 \mathrm{~kg} /$ $\mathrm{m}^{2}$ ), normal weight (BMI of $>17.0-24.0 \mathrm{~kg} / \mathrm{m}^{2}$ ), overweight (BMI of $>24-29.0 \mathrm{~kg} / \mathrm{m}^{2}$ ), or obese $($ BMI $>29.0$ $\mathrm{kg} / \mathrm{m}^{2}$ ) and the proportions of subjects in these categories were computed separately for boys and girls.

Depression was measure using the ADRS, specifically developed to measure the intensity of depression among adolescents. This measure was previously validated on young people aged 12 to 20 and published with the official cut-off [25]. It is a 10-item self-administered questionnaire with yes/no responses concerning the two weeks preceding completion. The sum of item scores provides a score that divides the population into three distinct groups: score 0 to 2 "not depressed", 3 to 5 "sub-threshold depression", and 6 or more "depressed". The cutoff of 6 was chosen because it provides maximum sensitivity and specificity in screening for major depressive state according to DSM-IV with clinically relevant intensity, which corresponds to a CGI score (Clinical Global Impression) of 5 or more (i.e. markedly ill or more). The corresponding subjects are therefore termed "depressed" here. The group with a score of 3-5 is the sub-threshold group as defined in [25]. We used categorical data only for descriptive analyses but we used continuous data to investigate associations between ADRS and BMI.

Parental working and marital status were based on adolescent reports.

\section{Statistical analysis}

Data are presented as means and standard deviation or percentages. Descriptive statistics were compared using Student $\mathrm{t}$-test or the chi-square test.

The association between BMI and ADRS was studied using a thin-plate penalized regression spline model. This statistical method is based on the estimation of a general additive model with a penalized regression spline. This model is similar to a linear regression 
model with a dependant variable (here the ADRS score as a continuous numerical variable) and an explanatory variable (here $\mathrm{BMI}$ ). But in contrast to linear regression, the explanatory variable BMI is not analysed per se, it is optimised using a piecewise cubic spline function. This cubic spline function aims to find the best-fitting curve representing the link between the dependent and independent variables, using cubic polynomials on a succession of consecutive intervals [28]. To avoid overparameterization of the fitted model, a constraint is added to the algorithm, giving a so-called penalized regression spline model. The $\mathrm{R}$ software and the " $\mathrm{mgcv}$ " package were used for the analyses [29]. To statistically test the "inversion of convexity" observed in the regression spline between BMI and ADRS scores, a polynomial regression was estimated. More precisely, for a BMI between 25 and 35, ADRS was regressed against BMI expressed with 3 orthogonal polynomials of degrees respectively equal to 1,2 and 3 . The hypothesis was that the component of degree 3 should be statistically significant. A probability level of $\mathrm{P}<0.05$ was used to indicate statistical significance. The association was controlled for parental working and marital status in the linear part of the regression model, which is therefore semi-parametric.

\section{Results}

Of the total sample $(\mathrm{n}=39542), 49.7 \%$ were girls and $50.3 \%$ were boys. $92.8 \%$ of the parents had a professional activity and $71.2 \%$ were living together.

Our results show that the distribution of the sample across BMI categories differed significantly between boys and girls $(\mathrm{p}<0.001)$. The prevalence of « thin » subjects was higher among girls than boys ( $4.0 \%$ versus $2.2 \%)$, the prevalence of overweight was higher among boys than girls $(12.9 \%$ versus $8.7 \%)$ while the difference in the prevalence of obesity was not statistically significant $(2.1 \%$ versus 1.8\%) (Table 1). Prevalence of overweight and obesity was higher when the parents were not working $(\mathrm{p}<$ 0.001 ) for both genders. We found a significant difference according to parental matrimonial status for the girls $(\mathrm{p}=$ 0.044) but not for the boys (Table 2).

Concerning depression, the mean score on the ADRS was significantly higher for girls compared to boys ( $\mathrm{p}<$ 0.001 ). The proportion of depressed girls (ADRS score $\geq$ 6) $(10.4 \%)$ was greater than that for boys $(4.5 \%)$ ( $\mathrm{p}<$ 0.001 , Table 1). The prevalence of depression was significantly higher when parents were not working $(\mathrm{p}<$ $0.001)$, and when parents were separated $(\mathrm{p}<0.001)$ for the two depression groups, sub-threshold and depressed for boys and for girls (Table 3).

Depression and BMI were significantly associated in both the total sample, and in boys and girls separately $(\mathrm{P}<0.0001$ in all three samples $)$. In addition, the
Table 1 Demography, anthropometry and depression

\begin{tabular}{|c|c|c|c|}
\hline & $\begin{array}{c}\text { Boys } \\
\mathrm{n}=19884\end{array}$ & $\begin{array}{c}\text { Girls } \\
\mathrm{n}=19658\end{array}$ & $\begin{array}{c}\text { Total } \\
\mathrm{n}=39542\end{array}$ \\
\hline \multicolumn{4}{|l|}{ Demography } \\
\hline Age years (sd) & $17.1(0.29)$ & $17.1(0.27)$ & $17.1(0.28)$ \\
\hline \multicolumn{4}{|l|}{ Parents working $\%$} \\
\hline yes & 93.2 & 92.4 & 92.8 \\
\hline no & 6.8 & 7.6 & 7.2 \\
\hline \multicolumn{4}{|c|}{ Parents together $\%$} \\
\hline yes & 71.1 & 71.2 & 71.2 \\
\hline no (1) & 28.8 & 28.7 & 28.8 \\
\hline \multicolumn{4}{|l|}{ Anthropometry } \\
\hline$\overline{\text { Weight Kg (sd) }}$ & $67.6(10.3)$ & $56.3(8.5)$ & $62.0(11.0)$ \\
\hline Height cm (sd) & $177.3(7.0)$ & $164.9(6.3)$ & $171.1(9.1)$ \\
\hline BMI mean (sd) & $21.5(2.9)$ & $20.7(3.0)$ & $21.1(3.0)$ \\
\hline \multicolumn{4}{|l|}{ BMI category, \% } \\
\hline$<=17.0$ & 2.2 & 4.0 & 3.1 \\
\hline$>17.0-24.0$ & 82.8 & 85.5 & 84.1 \\
\hline$>24.0-29.0$ & 12.9 & 8.7 & 10.8 \\
\hline$>29$ & 2.1 & 1.8 & 1.9 \\
\hline \multicolumn{4}{|l|}{ Depression } \\
\hline ADRS mean (sd) & $1.3(1.9)$ & $2.2(2.3)$ & $1.7(2.1)$ \\
\hline \multicolumn{4}{|l|}{ ADRS score \% } \\
\hline $0-2$ & 80.2 & 64.0 & 72.0 \\
\hline $3-5$ & 15.2 & 25.5 & 20.0 \\
\hline$>=6$ & 4.5 & 10.4 & 7.5 \\
\hline
\end{tabular}

Source: ESCAPAD 2008, OFDT

(1) This category includes young people whose parents are divorced or separated for other reasons, and also those who have lost one or both parents

Notes: $\mathbf{s d}=$ standard deviation;

association was not linear and the curve presented a different shape for boys and girls. (Figure 1A and 1B). Among boys, the U-shaped curve demonstrated that both obesity and underweight were associated with an increased level of depression (Figure 1A). Among girls, the curve showed a first part of the curve describing a $\mathrm{U}$ shape and then inverted convexity for higher BMI levels (Figure 1B) indicating that overweight adolescent girls were more likely to be depressed than obese adolescent girls.

In order to test whether this inversion of convexity observed in girls with BMI between 25 and 35 was statistically significant, we used a linear regression model with orthogonal polynomials. More precisely, for girls with BMI between 25 and 35, the ADRS score was regressed against BMI expressed with a linear quadratic and cubic component. The inversion of convexity corresponds, from a statistical point of view, to the cubic component, which was statistically significant here with $p=0.003$ (the linear and quadratic components are not significant at the $5 \%$ level). The association did not alter when working and marital status were controlled for. 
Table 2 Parental status and BMI

\begin{tabular}{|c|c|c|c|c|c|c|c|c|}
\hline & \multicolumn{4}{|c|}{ BMI category Boys } & \multicolumn{4}{|c|}{ BMI category Girls } \\
\hline & Under weight & Normal & Over weight & Obese & Under weight & Normal & Over weight & Obese \\
\hline & $<=17$ & $>17-24$ & $>24-29$ & $>29$ & $<=17$ & $>17-24$ & $>24-29$ & $>29$ \\
\hline \multicolumn{9}{|c|}{ Parents working } \\
\hline yes & 2.2 & 83.3 & 12.6 & 1.9 & 4.1 & 86.0 & 8.3 & 1.6 \\
\hline No & 2.1 & 79.4 & 15.6 & 3.0 & 3.1 & 80.0 & 12.7 & 4.3 \\
\hline \multicolumn{9}{|c|}{ Parents together } \\
\hline Yes & 2.4 & 82.9 & 12.7 & 2.1 & 4.2 & 85.7 & 8.3 & 1.8 \\
\hline no (2) & 1.9 & 83.1 & 13.0 & 2.1 & 3.4 & 85.2 & 9.5 & 1.9 \\
\hline
\end{tabular}

Source: ESCAPAD 2008, OFDT

(2) This category includes young people whose parents are divorced or separated for other reasons, and those who have lost one or both parents.

\section{Discussion}

Obesity and depressive disorders are central public health issues and the relationship between depression and weight remains unclear [1,2].

Our study shows that irrespective of gender, the prevalence of overweight and obesity at 17 years of age is respectively $10.8 \%$ and $1.9 \%$. Figures in France at age 14 are $7 \%$ for overweight and $4 \%$ for obesity [30,31]. According to gender, the present results show a prevalence of overweight ( $12.9 \%$ for boys and $8.7 \%$ for girls) that is comparable to that found in the international literature, ranging from $5.2 \%$ to $28.9 \%$ for boys and from $8.1 \%$ to $31.0 \%$ for girls [19]. As in the literature, we found differences in prevalence according to parental professional status and parental marital status [6,30,31].

The prevalence of depression in the present study on the basis of the ADRS measure specific to adolescents was $4.5 \%$ among boys and $10.4 \%$ among girls. In the literature, the data on prevalence of depression varies, in particular according to the type of measure used (measures of intensity, or DSM-IV-based) as well as according to whether or not gender differences are sought. In France, using criteria for depression according to a standardized assessment (CIDI short form), the prevalence of depression for the age of 15 to 24 years old as been reported to range from $6.3 \%$ for boys, to $11.2 \%$ for girls [32]. A review of recent epidemiological studies showed prevalence rates ranging from $1.8 \%$ to $5.9 \%$ in the United States [33-35]. For the years 2005-2006, the Center for Disease Control found a prevalence of depression between $4 \%$ and $6.4 \%$ for ages 12 to 17 , using the PHQ9, but without testing for gender differences [36]. Many epidemiological and clinical studies have shown that girls have typically been found to display higher levels of depressive symptoms than boys $[37,38]$. This has been attributed to genetics, increased prevalence of anxiety disorders in females, biological changes associated with puberty, cognitive predisposition and socio-cultural factors [39].

The most important result of our study concerns the non-linear and significant association between depression and BMI, with no effect of parental working and marital status. In addition, the shape of the association is different for boys and girls. We have a U-shaped association for boys, which shows that boys that are too thin or too fat have higher levels of depression. For girls, we have a beginning of a $U$ shape, and then an inversely convex curve, which means, first, that depression levels in underweight girls are higher than in normal weight girls, and second, that depression levels are higher in overweight adolescent girls than in obese girls. This can be related to the "fat and jolly" hypothesis, which has been discussed for older women [40-42]. Our results recall the study by Wardle et al [19], who found,

Table 3 Parental status and depression

\begin{tabular}{|c|c|c|c|c|c|c|}
\hline & \multicolumn{3}{|c|}{ ADRS score Boys } & \multicolumn{3}{|c|}{ ADRS score Girls } \\
\hline & $\begin{array}{l}\text { Not depressed } \\
0-2\end{array}$ & $\begin{array}{c}\text { Sub-threshold depressed } \\
3-5\end{array}$ & $\begin{array}{l}\text { Depressed } \\
\quad \geq 6\end{array}$ & $\begin{array}{c}\text { Not depressed } \\
0-2\end{array}$ & $\begin{array}{c}\text { Sub-threshold depressed } \\
3-5\end{array}$ & $\begin{array}{l}\text { Depressed } \\
\geq 6\end{array}$ \\
\hline \multicolumn{7}{|c|}{ Parents working } \\
\hline yes & 80.7 & 15.0 & 4.3 & 64.9 & 25.2 & 10.0 \\
\hline no & 76.7 & 17.4 & 5.9 & 57.4 & 29.1 & 13.6 \\
\hline \multicolumn{7}{|c|}{ Parents together } \\
\hline yes & 81.3 & 14.6 & 4.2 & 65.8 & 24.5 & 9.7 \\
\hline no (2) & 77.6 & 17.1 & 5.3 & 60.4 & 27.8 & 11.8 \\
\hline
\end{tabular}

Source: ESCAPAD 2008, OFDT

(2) This category includes young people whose parents are divorced or separated for other reasons, and those who have lost one or both parents. 


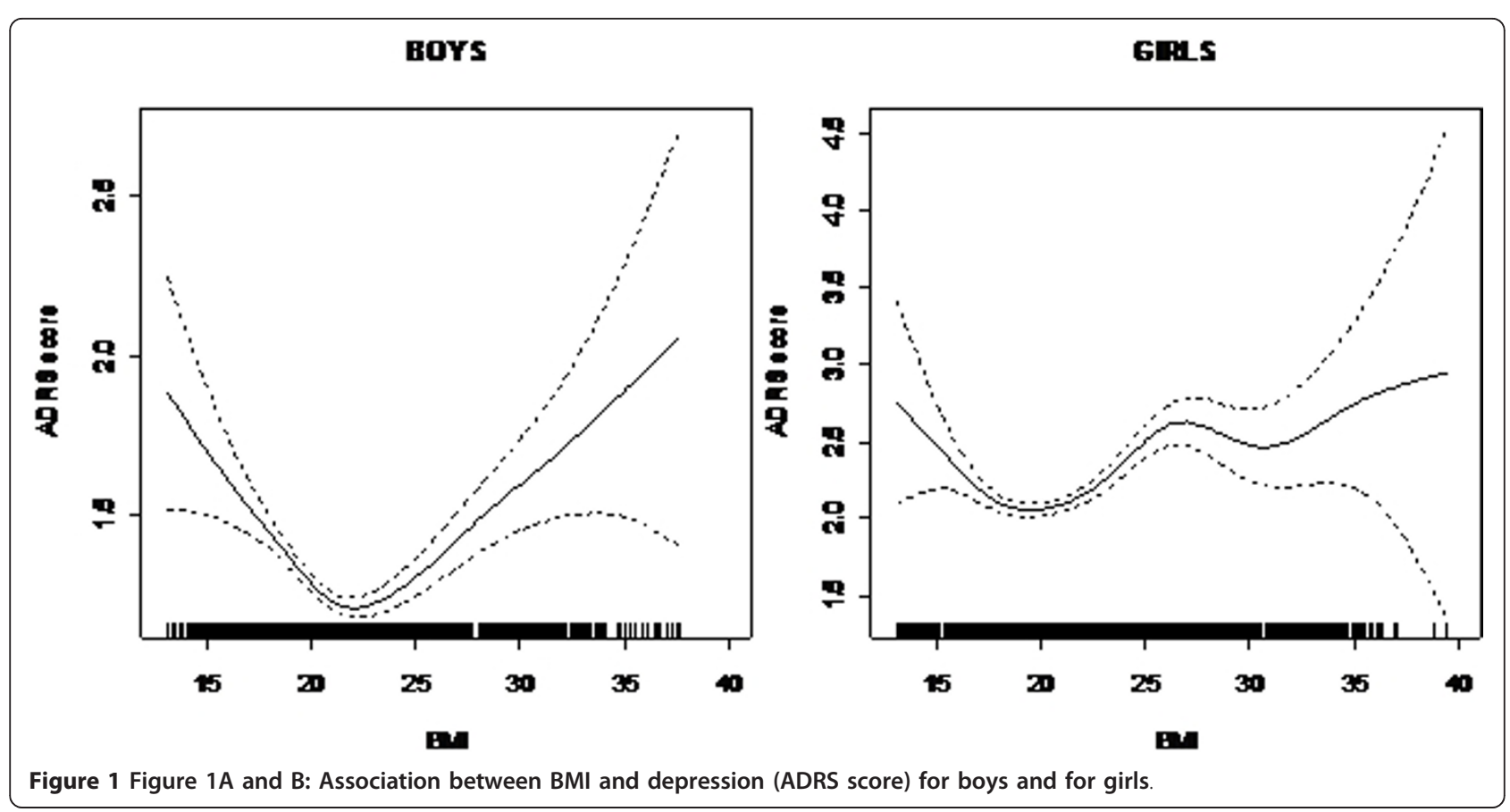

in a small sample of adolescents, that regardless of moderators reports of depressive symptoms were more frequent in overweight than in obese adolescent girls of 14, and who found no difference for depressive symptoms between normal weight and obese girls. Using splines, Cortese [5] in a small sample found curves of different shape for boys and a U-shaped curve for girls aged 11 to 14 , showing that underweight girls had an equivalent level of depression to that of obese girls, this not being true for the boys. While some previous studies have explored the association between obesity and depression without questioning the gender difference $[23,43,44]$, according to the recent meta-analysis of communitybased studies by de Wit et al [14] there is some support for the hypothesis that there is a difference between males and females in the association.

The "fat and jolly" hypothesis, which we suggest for the adolescent girls of 17 years old, is generally thought to be related to hormone and neuro-endocrine issues, but it could be envisaged as a possible dynamic in adolescent girls. It can indeed be thought that the difficult struggle against excess weight could let up when the subject reaches the obesity stage, as if, once they give up the struggle, they may feel less depressed. In all events, obesity, despite creating negative social experiences in adolescence, does not in itself cause depression. The effect of moderators needs to be explored in the association between weight and depression, and in particular the complex association between weight and the perception of weight, as a risk factor of depression $[45,46]$.
Several limitations of the study must be considered. BMI was calculated from self-report, with the attendant risk of under-estimation of weight. The degree of divergence between subjective and objective BMI has been described for different ages, different countries and according to gender [47]. However, most studies use selfreport data. The underestimation tends to be greater among obese adolescents, so that the prevalence in our study may well be underestimated. Secondly, as our study is cross-sectional, we cannot demonstrate the mechanisms of the association found. Only longitudinal studies are able to explore the different effects of the potential moderators of the association, and investigate the possible predictive relationship between overweight and depression. Indeed, longitudinal studies can provide evidence for depression predicting future obesity or weight gain or the reverse. Published research to date has shown a mixed picture $[11,48,49]$. Thirdly, we have no data available about race or ethnicity because no studies in France are allowed to ask questions about theses major factors in public health. Moreover, the present data only concerns French nationals from metropolitan France (i.e. excluding overseas territories). However the sample nevertheless represents 5.2\% of the French metropolitan population aged 17, and is representative of it.

Overall, since the results are derived in part from the visual examination of regression splines, they should be considered basically as exploratory, and therefore as requiring replication. Despite these limitations, this study provides valuable information on account of the 
exceptionally large size of the sample. To our knowledge, this is the very first survey worldwide on such a large representative sample of a total population of adolescents. And another important point is that while most studies use depression measures comprising items concerning the body, food, or weight, which are confounders in the exploration of the links between depression and weight, in the present study we used the ADRS measure of depression, which is the only measure that does not contain these confounders.

\section{Conclusion}

These results point to the importance of distinguishing between girls and boys when we investigate the nature of the association between depression and the four different BMI categories. It also shows that overweight adolescent girls are at higher risk of depression than the obese adolescent girls.

\section{Acknowledgements \\ We thank Angela Verdier for her help in the English wording of the manuscript. The OFDT (Observatoire Français des Drogues et des Toxicomanies) and the French Ministry of Defense for their implication in the collection of data.}

\section{Author details \\ 'INSERM, U-669 PSIGIAM, Paris, F-75679, France. ${ }^{2}$ Univ. Paris-Sud, Univ. Paris- Descartes, Paris, F-75005, France. ${ }^{3}$ Centre de Soins Psychothérapeutiques de Transition pour Adolescents, Hôpital d'Argenteuil, F-95107, Argenteuil, France. ${ }^{4}$ Centre Hospitalier de Versailles. Service de Pédopsychiatrie. Le Chesnay, France. ${ }^{5}$ AP-HP, Direction de la Politique médicale, Paris F-75004, France. ${ }^{6}$ AP-HP, Hôpital Cochin, Maison de Solenn, Paris, F-75014, France. ${ }^{7}$ AP-HP, Hôpital Paul Brousse, Département de Santé Publique, Villejuif, F- 94804, France.}

\section{Authors' contributions}

ARL wrote the first draft and the revisions of the manuscript. MS, $\mathrm{CH}$ and $\mathrm{CB}, \mathrm{BF}$ conducted the statistical analyses. MS, IG, BF, MRM critically read each draft and contributed to the further drafting and revisions of the manuscript. All authors read and approved the final manuscript.

\section{Competing interests}

The authors declare that they have no competing interests.

Received: 22 March 2011 Accepted: 16 August 2011

Published: 16 August 2011

\section{References}

1. Faith MS, Matz PE, Jorge MA: Obesity-depression associations in the population. J Psychosom Res 2002, 53(4):935-942.

2. McElroy SL, Kotwal R, Malhotra S, Nelson EB, Keck PE, Nemeroff CB: Are mood disorders and obesity related? A review for the mental health professional. J Clin Psychiatry 2004, 65(5):634-651, quiz 730.

3. Ogden $C L$, Carroll MD, Curtin LR, Lamb MM, Flegal KM: Prevalence of high body mass index in US children and adolescents, 2007-2008. JAMA 2010, 303(3):242-249.

4. Wardle J, Cooke L: The impact of obesity on psychological well-being. Best Pract Res Clin Endocrinol Metab 2005, 19(3):421-440.

5. Goodman E, Slap GB, Huang B: The public health impact of socioeconomic status on adolescent depression and obesity. Am J Public Health 2003, 93(11):1844-1850.

6. Sjöberg RL, Nilsson KW, Leppert J: Obesity, shame, and depression in school-aged Children: A population-based study. PEDIATRICS 2005, 116(3): e389-e392.
7. de Wit LM, Fokkema M, van Straten A, Lamers F, Cuijpers P, Penninx BW: Depressive and anxiety disorders and the association with obesity, physical, and social activities. Depress Anxiety 2010, 27(11):1057-1065.

8. Blum RW, Beuhring T, Shew ML, Bearinger LH, Sieving RE, Resnick MD: The effects of race/ethnicity, income, and family structure on adolescent risk behaviors. Am J Public Health 2000, 90(12):1879-1884.

9. BeLue R, Francis LA, Colaco B: Mental health problems and overweight in a nationally representative sample of adolescents: effects of race and ethnicity. PEDIATRICS 2009, 123(2):697-702.

10. Gray VB, Byrd SH, Cossman JS, Chromiak J, Cheek WK, Jackson GB: Family characteristics have limited ability to predict weight status of young children. J Am Diet Assoc 2007, 107(7):1204-1209.

11. Goodman e, Whitaker RC: A prospective study of the role of depression in the development and persistence of adolescent obesity. Pediatrics 2002, 109(3):497-504.

12. Luppino FS, de Wit LM, Bouvy PF, Stijnen T, Cuijpers P, Penninx BW Zitman FG: Overweight, obesity, and depression: a systematic review and meta-analysis of longitudinal studies. Arch Gen Psychiatry 2010, 67(3):220-229

13. Pine DS, Cohen P, Brook J, Coplan JD: Psychiatric symptoms in adolescence as predictors of obesity in early adulthood: a longitudinal study. Am J Public Health 1997, 87(8):1303-1310.

14. de Wit L, Luppino F, van Straten A, Penninx B, Zitman F, Cuijpers P: Depression and obesity: a meta-analysis of community-based studies. Psychiatry Res 2010, 178(2):230-235.

15. Becker ES, Margraf J, Turke V, Soeder U, Neumer S: Obesity and mental illness in a representative sample of young women. Int J Obes Relat Metab Disord 2001, 25(Suppl 1):S5-9.

16. Baumeister $\mathrm{H}$, Harter M: Mental disorders in patients with obesity in comparison with healthy probands. Int J Obes (Lond) 2007, 31(7):1155-1164

17. Cortese S, Falissard B, Angriman M, Pigaiani Y, Banzato C, Bogoni G, Pellegrino M, Cook S, Pajno-Ferrara F, Bernardina BD, et al: The relationship between body size and depression symptoms in adolescents. J Pediatr 2009, 154(1):86-90.

18. Richardson LP, Garrison MM, Drangsholt M, Mancl L, LeResche L: Associations between depressive symptoms and obesity during puberty. Gen Hosp Psychiatry 2006, 28(4):313-320.

19. Wardle J, Williamson S, Johnson F, Edwards C: Depression in adolescent obesity: cultural moderators of the association between obesity and depressive symptoms. Int J Obes (Lond) 2006, 30(4):634-643.

20. Han TS, Tijhuis MA, Lean ME, Seidell JC: Quality of life in relation to overweight and body fat distribution. Am J Public Health 1998, 88(12):1814-1820.

21. Kress AM, Peterson MR, Hartzell MC: Association between obesity and depressive symptoms among U.S. Military active duty service personnel, 2002. J Psychosom Res 2006, 60(3):263-271.

22. Carpenter KM, Hasin DS, Allison DB, Faith MS: Relationships between obesity and DSM-IV major depressive disorder, suicide ideation, and suicide attempts: results from a general population study. Am J Public Health 2000, 90(2):251-257.

23. de Wit LM, van Straten A, van Herten M, Penninx BW, Cuijpers P: Depression and body mass index, a u-shaped association. BMC Public Health 2009, 9:14.

24. Johnston $E$, Johnson $S$, McLeod $P$, Johnston M: The relation of body mass index to depressive symptoms. Can J Public Health 2004, 95(3):179-183.

25. Revah-Levy A, Birmaher B, Gasquet I, Falissard B: The Adolescent Depression Rating Scale (ADRS): a validation study. BMC Psychiatry 2007, 7:2.

26. Acquaviva E, Legleye S, Auleley GR, Deligne J, Carel D, Falissard BB: Psychotropic medication in the French child and adolescent population: prevalence estimation from health insurance data and national selfreport survey data. BMC Psychiatry 2009, 9:72.

27. Butte NF, Garza C, de Onis M: Evaluation of the feasibility of international growth standards for school-aged children and adolescents. J Nutr 2007, 137(1):153-157.

28. Wood S, Augustin N: GAMs with integrated model selection using penalized regression splines and application to environmental modelling. Ecol Model 2002, 157:157-177.

29. R RDCT: A language and Environment for Statistical Computing. Vienna Austria: R Development Core Team; 2006. 
30. Guignon N: La santé des adolescents en classe de 3 en 2003-2004. Premiers résultats. Etudes et Résultats, DREES 2007, n573.

31. INSERM (ed.): Obesité, dépistage, prévention chez l'enfant. Paris; 2000.

32. Lamboy B: Barometre santé premiers résultats. INPES: INPES; 2005.

33. Costello EJ, Foley DL, Angold A: 10-year research update review: the epidemiology of child and adolescent psychiatric disorders: II. Developmental epidemiology. J Am Acad Child Adolesc Psychiatry 2006, 45(1):8-25.

34. Angold A, Erkanli A, Silberg J, Eaves L, Costello EJ: Depression scale scores in 8-17-year-olds: effects of age and gender. J Child Psychol Psychiatry 2002, 43(8):1052-1063.

35. Kessler RC, Avenevoli S, Ries Merikangas K: Mood disorders in children and adolescents: an epidemiologic perspective. Biol Psychiatry 2001, 49(12):1002-1014.

36. Pratt LBDJ: Depression in the United States Household Population, 20052006. NCHS Data Brief. 2008 edition. Center for Disease Control and Prevention; 2008.

37. Compas BE, Oppedisano G, Connor JK, Gerhardt CA, Hinden BR, Achenbach TM, Hammen C: Gender differences in depressive symptoms in adolescence: comparison of national samples of clinically referred and nonreferred youths. J Consult Clin Psychol 1997, 65(4):617-626.

38. Essau CA, Lewinsohn PM, Seeley JR, Sasagawa S: Gender differences in the developmental course of depression. J Affect Disord 127(1-3):185-190.

39. Breslau N, Peterson EL, Schultz LR, Chilcoat HD, Andreski P: Major depression and stages of smoking. A longitudinal investigation. Arch Gen Psychiatry 1998, 55(2):161-166.

40. Jasienska G, Ziomkiewicz A, Gorkiewicz M, Pajak A: Body mass, depressive symptoms and menopausal status: an examination of the "Jolly Fat" hypothesis. Womens Health Issues 2005, 15(3):145-151.

41. Roberts RE, Strawbridge WJ, Deleger S, Kaplan GA: Are the fat more jolly? Ann Behav Med 2002, 24(3):169-180.

42. Palinkas $L A$, Wingard $D L$, Barrett-Connor E: Depressive symptoms in overweight and obese older adults: a test of the "jolly fat" hypothesis. J Psychosom Res 1996, 40(1):59-66.

43. Erickson SJ, Robinson TN, Haydel KF, Killen JD: Are overweight children unhappy?: Body mass index, depressive symptoms, and overweight concerns in elementary school children. Arch Pediatr Adolesc Med 2000, 154(9):931-935.

44. Onyike cu, Crum Rm, Lee hb, Lyketsos cg, Eaton ww: Is obesity associated with major depression? Results from the third National health and nutrition examination survey. Am J Epidemiol 2003, 158(12):1139-1147.

45. Pesa JA, Syre TR, Jones E: Psychosocial differences associated with body weight among female adolescents: the importance of body image. $J$ Adolesc Health 2000, 26(5):330-337.

46. ter Bogt TF, van Dorsselaer SA, Monshouwer $K$, Verdurmen JE, Engels RC, Vollebergh WA: Body mass index and body weight perception as risk factors for internalizing and externalizing problem behavior among adolescents. J Adolesc Health 2006, 39(1):27-34.

47. Kurth BM, Ellert U: Estimated and measured BMI and self-perceived body image of adolescents in Germany: part 1 - general implications for correcting prevalence estimations of overweight and obesity. Obes Facts 2010, 3(3):181-190.

48. Anderson SE, Cohen P, Naumova EN, Jacques PF, Must A: Adolescent obesity and risk for subsequent major depressive disorder and anxiety disorder: prospective evidence. Psychosom Med 2007, 69(8):740-747.

49. Boutelle KN, Hannan P, Fulkerson JA, Crow SJ, Stice E: Obesity as a prospective predictor of depression in adolescent females. Health Psychol 2010, 29(3):293-298.

\section{Pre-publication history}

The pre-publication history for this paper can be accessed here: http://www.biomedcentral.com/1471-2458/11/649/prepub

\section{doi:10.1186/1471-2458-11-649}

Cite this article as: Revah-Levy et al:: Association between Body Mass Index and depression: the "fat and jolly" hypothesis for adolescents girls. BMC Public Health 2011 11:649.

\section{Submit your next manuscript to BioMed Central and take full advantage of:}

- Convenient online submission

- Thorough peer review

- No space constraints or color figure charges

- Immediate publication on acceptance

- Inclusion in PubMed, CAS, Scopus and Google Scholar

- Research which is freely available for redistribution

Submit your manuscript at www.biomedcentral.com/submit
Biomed Central 